\title{
Characteristics of children admitted to hospital with acute SARS-CoV-2 infection in Canada in 2020
}

\author{
Olivier Drouin MDCM MSc MPH, Charlotte Moore Hepburn MD, Daniel S. Farrar MPH, Krista Baerg BSN MD, \\ Kevin Chan MD MPH, Claude Cyr MD MSc, Elizabeth J. Donner MD MSc, Joanne E. Embree MD, Catherine Farrell MD, \\ Sarah Forgie MD MEd, Ryan Giroux MD, Kristopher T. Kang MD, Melanie King BA, Melanie Laffin BCom, \\ Thuy Mai Luu MD MSc, Julia Orkin MD MSc, Jesse Papenburg MD MSc, Catherine M. Pound MD MSc, \\ Victoria E. Price MBChB MSc, Rupeena Purewal MD, Manish Sadarangani BM BCh DPhil, Marina I. Salvadori MD, \\ Karina A. Top MD MS, Isabelle Viel-Thériault MD, Fatima Kakkar MD MPH, Shaun K. Morris MD MPH; \\ for the Canadian Paediatric Surveillance Program COVID-19 Study Team
}

Cite as: CMAJ 2021 September 27;193:E1483-93. doi: 10.1503/cmaj.210053

See related article at www.cmaj.ca/lookup/doi/10.1503/cmaj.211513

\section{Abstract \\ Background: Risk factors for severe out- comes of SARS-CoV-2 infection are not well established in children. We sought to describe pediatric hospital admis- sions associated with SARS-CoV-2 infec- tion in Canada and identify risk factors for more severe disease.}

Methods: We conducted a national prospective study using the infrastructure of the Canadian Paediatric Surveillance Program (CPSP). Cases involving children who were admitted to hospital with microbiologically confirmed SARS-CoV-2 infection were reported from Apr. 8 to Dec. 31 2020, through weekly online questionnaires distributed to the CPSP network of more than 2800 pediatri- cians. We categorized hospital admissions as related to COVID-19, incidental, or for social or infection control reasons and determined risk factors for disease severity in hospital.

Results: Among 264 hospital admissions involving children with SARS-CoV-2 infection during the 9-month study period, 150 (56.8\%) admissions were related to COVID-19 and 100 (37.9\%) were incidental infections (admissions for other reasons and found to be positive for SARS-CoV-2 on screening). Infants (37.3\%) and adolescents (29.6\%) represented most cases. Among hospital admissions related to COVID-19, 52 (34.7\%) had critical disease, 42 (28.0\%) of whom required any form of respiratory or hemodynamic support, and 59 (39.3\%) had at least 1 underlying comorbidity. Children with obesity, chronic neurologic conditions or chronic lung disease other than asthma were more likely to have severe or critical COVID-19.

Interpretation: Among children who were admitted to hospital with SARSCoV-2 infection in Canada during the early COVID-19 pandemic period, incidental SARS-CoV-2 infection was common. In children admitted with acute COVID-19, obesity and neurologic and respiratory comorbidities were associated with more severe disease.

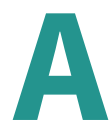

S of Dec. 31, 2020, Canada had 581427 confirmed cases of SARS-CoV-2 infection. ${ }^{1}$ Similar to other countries, most confirmed infections were in adults, in part because of initial testing policies that targeted older and at-risk populations, as well as prolonged societal containment measures to minimize children's risk of exposure. Although fewer SARS-CoV-2 infections in children were reported relative to adults during Canada's first waves of the pandemic, ${ }^{2}$ recent surges in pediatric cases across North America have challenged the notion that children are infected at a lower frequency than adults. ${ }^{3,4}$ However, the severity of infection in children appears to be substantially lower, with fewer overall hospital admissions reported and substantially lower mortality compared with adults. ${ }^{5,6}$

Although risk factors for more severe outcomes of COVID-19 have been well described in adults, ${ }^{7}$ similar risks are less well described in children. ${ }^{8}$ Experience with other viral respiratory infections, including influenza and respiratory syncytial virus, has shown that patient-level factors can increase risk for severe disease in children. ${ }^{9,10}$ Understanding populations at risk for severe 
disease is essential for developing evidence-informed testing strategies, recommendations around reducing exposure (including guidance informing in-person schooling) and potential prioritization of SARS-CoV-2 vaccines in children.

To date, few published data have characterized admissions to hospital with SARS-CoV-2 infection among children in Canada. We sought to describe pediatric hospital admissions associated with acute SARS-CoV-2 infection in Canada and identify risk factors for severe disease among children admitted to hospital.

\section{Methods}

\section{The Canadian Paediatric Surveillance Program}

The Canadian Paediatric Surveillance Program (CPSP), a joint project of the Canadian Paediatric Society and the Public Health Agency of Canada (PHAC), is a platform for public health surveillance that was designed to support national prospective pediatric studies. ${ }^{11}$ Using online case reporting, the CPSP gathers information on specific pediatric diseases through its network of more than 2800 pediatricians and pediatric subspecialists from across Canada, representing most of the providers of pediatric care in the country. ${ }^{11,12}$

In March 2020, at the onset of the COVID-19 pandemic, a CPSP COVID-19 study group was assembled, including representatives from academic and community pediatric centres from all regions of Canada. The study was designed to collect patient-level detail on 3 different groups: children admitted to hospital with acute SARS-CoV-2 infection (reported here), children with SARS-CoV-2 infection who were not admitted to hospital but who were younger than 1 year or had an underlying comorbidity and children with pediatric inflammatory multisystem syndrome associated with COVID-19 (launched in May 2020). ${ }^{13,14}$ This analysis includes all reported cases to Dec. 31, 2020. The study protocol, including case definitions and case report form, is available at https://www.cpsp.cps.ca/surveillance/study-etude/covid-19 (Appendix 1, available at www.cmaj.ca/lookup/doi/10.1503/ cmaj.210053/tab-related-content).

Beginning on Apr. 8, 2020, CPSP participants were asked to report all cases encountered in the previous 7 days involving children younger than 18 years of age who were admitted to hospital with acute, microbiologically confirmed SARS-CoV-2 infection, as well as all such cases that had not yet been reported. Participants who reported a case were asked to complete a case report form that included key demographic, epidemiologic, microbiologic and clinical data (including comorbidities).

Real-time case monitoring and data cleaning was conducted throughout the study period. When reporting a case, physicians could agree to further contact by the CPSP to clarify discrepant, missing or unclear data. If cases were reported in duplicate, records were compared and collapsed together using the most complete and accurate data from each record.

\section{Case classification and severity}

For all children with acute microbiologically confirmed SARSCoV-2 infection and clinical data reported, we classified the cases into 1 of the following mutually exclusive categories: related to COVID-19, that is, a child admitted to hospital with clinical disease that was determined to be directly related to SARS-CoV-2 infection; incidental infection, that is, SARS-CoV-2 infection identified in a child admitted to hospital for an unrelated reason (e.g., fracture) and the infection did not alter the course of admission; or related to social or isolation purposes, that is, SARS-CoV-2 infection identified in an asymptomatic or mildly symptomatic child who required hospital admission for isolation or social purposes (e.g., caregiver[s] was admitted to hospital). To ensure accuracy of case classification, at least 2 study team members (O.D., C.M.H., S.K.M. or F.K.), reviewed all available information on the case report form, including all additional diagnoses and interventions reported during the hospital admission. Any discrepancies in the assignment of category of disease were resolved by followup with the physician or by consensus.

We categorized disease severity using a modified version of the Dong criteria that were adapted to local practice (Appendix 2, available at www.cmaj.ca/lookup/doi/10.1503/cmaj.210053/tab -related-content). ${ }^{15,16}$ We defined case severity as follows: asymptomatic, that is, patients reported to have no signs or symptoms, with radiologic findings normal or not conducted; mild disease, that is, symptomatic but without respiratory distress or abnormal radiology; moderate disease, that is, patients with lower respiratory tract disease, hematologic abnormalities or abnormal findings on radiologic examination but lacking other organ involvement and need for respiratory support; severe disease, that is, patients with respiratory distress or requiring supplemental oxygen; or critical disease, that is, patients admitted to the intensive care unit (ICU), requiring ventilation or experiencing clinical features of shock or other organ involvement. For analysis, we combined severe and critical categories as severe disease and mild and moderate categories as nonsevere disease. To categorize patients, details of reported radiologic findings were independently assessed by 2 investigators (O.D., C.M.H., S.K.M. or F.K.) and categorized as abnormal, abnormal but not related to SARS-CoV-2, nonspecific, or normal. Any discrepancy was resolved by consensus.

\section{Statistical analysis}

We analyzed demographic characteristics using frequencies, percentages, medians and interquartile ranges. We categorized age as infant $(<1 \mathrm{yr}$ ), preschool (1-5 yr), school age (6-12 yr) or adolescent (13-17 yr). Primary analyses included only cases admitted to hospital for COVID-19. We analyzed the following case characteristics: severity, comorbidities, signs and symptoms, concurrent infections, imaging and treatment(s). For age, sex, severity, and prematurity variables, we conducted the analyses as complete case and indicated the proportion of missing data in table footnotes. For all other variables, we imputed missing or unknown data to the null value and included these in the denominators. We assessed differences in age groups and severity categories using Fisher exact tests or $\chi^{2}$ tests. We used a significance threshold of $\alpha=0.05$ for all comparisons. We conducted the analyses using Stata (version 16.1). Because of CPSP policies, we reported frequencies between 1 and 4 as less than 5 
and presented some outcomes as ranges. In some instances, results of subgroup analyses are not shown to prevent backcalculation of frequencies less than 5 .

\section{Ethical approval}

The CPSP operates under legal authority derived from Section 4 of the Department of Health Act and Section 3 of the Public Health Agency of Canada Act. Ethics approval was obtained from the PHAC and Health Canada Research Ethics Board (REB 2020002P), The Hospital for Sick Children (REB 1000070001), the Institutional Review Board of the Centre Hospitalier Universitaire Sainte-Justine (IRB MP-21-2021-2901) and at individual sites, as required by local policies. In Quebec, the study was conducted as a multicentre study, with clinical data collected by study co-investigators.

\section{Results}

In total, 757 unique cases were reported to the CPSP with a date of diagnosis between Mar. 25 and Dec. 31, 2020, of which 264 met our study's case definition (admitted to hospital with acute SARS-CoV-2 infection) and were included in the analysis (Figure 1). Cases were reported from all provinces; however, full data capture was not possible for Alberta because of delays in securing the appropriate data-transfer agreements. Our study reports on $80.0 \%$ of all hospital admissions of patients younger than 18 years of age in Canada excluding Alberta (246/308) as reported to $\mathrm{PHAC}$ during our study's time period (unpublished data; source: case information received by PHAC from provinces and territories) and $68.6 \%$ in Canada with Alberta included. Most of these patients (all categories) were from Quebec ( $n=114$, $43.2 \%)$ and Ontario $(n=94,35.6 \%)$ (Table 1$)$, and were admitted to hospital either between April and June or between September and December 2020 (Figure 2).

There were more reported SARS-CoV-2 infections among infants (< $1 \mathrm{yr} ; n=97,37.3 \%)$ and adolescents (13-17 yr; $n=77$, $29.6 \%)$ than among preschool (1-5 yr; $n=44,16.9 \%)$ or schoolaged (6-12 yr; $n=42,16.2 \%)$ children. Using population denominators from Statistics Canada, ${ }^{17}$ this represents a minimum incidence of hospital admission with SARS-CoV-2 infection of 26.0, 2.3, 1.4 and 3.8 per 100000 population in the infant, preschooland school-aged children, and adolescent age groups, respectively. A similar distribution was seen among those admitted to hospital because of COVID-19 (Appendix 3, Supplementary Table S1, available at www.cmaj.ca/lookup/doi/10.1503/ cmaj.210053/tab-related-content). We found that severity of

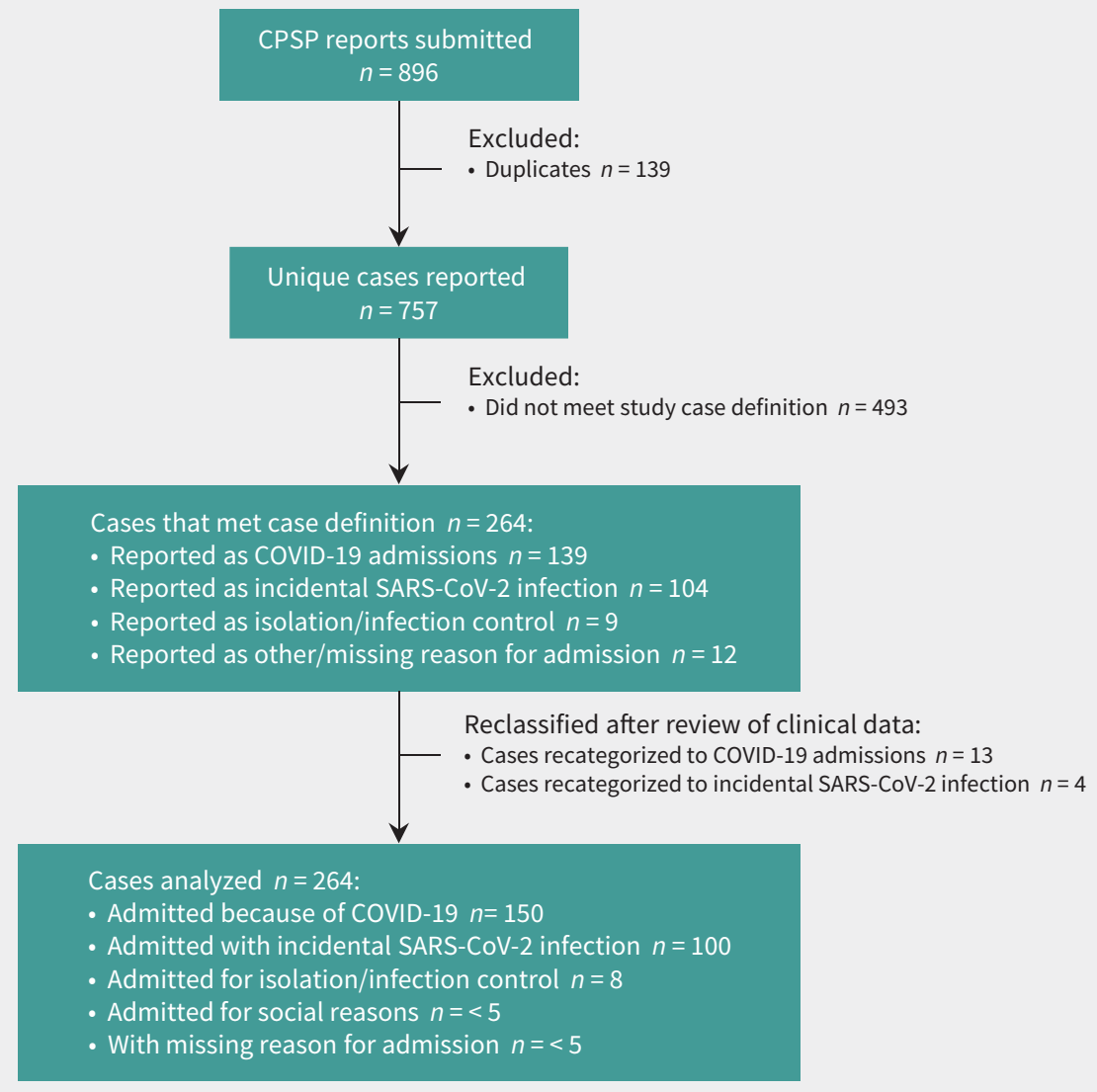

Figure 1: Flow chart of cases reported to the Canadian Paediatric Surveillance Program (CPSP) COVID-19 study with a diagnosis of SARS-CoV-2 infection on or before Dec. 31, 2020. 


\begin{tabular}{|c|c|c|c|c|c|}
\hline \multirow[b]{3}{*}{ Characteristic } & \multicolumn{4}{|c|}{ No. $(\%)$ of children } & \multirow[b]{3}{*}{$p$ valuet } \\
\hline & \multirow[b]{2}{*}{$\begin{array}{l}\text { All cases } \\
n=264\end{array}$} & \multirow{2}{*}{$\begin{array}{l}\text { Hospital admission } \\
\text { not related to } \\
\text { COVID-19 } \\
n=110\end{array}$} & \multicolumn{2}{|c|}{$\begin{array}{l}\text { Hospital admission related } \\
\text { to COVID-19*}\end{array}$} & \\
\hline & & & $\begin{array}{l}\text { Nonsevere disease } \\
\qquad n=75\end{array}$ & $\begin{array}{l}\text { Severe disease } \\
\qquad n=75\end{array}$ & \\
\hline Age, yr $\ddagger$ & & & & & 0.001 \\
\hline Infants (<1) & $97(37.3)$ & $34(31.5)$ & $42(56.8)$ & $21(28.0)$ & - \\
\hline Preschool (1-5) & $44(16.9)$ & $21(19.4)$ & $12(16.2)$ & $11(14.7)$ & - \\
\hline School age (6-12) & $42(16.2)$ & $15(13.9)$ & $8(10.8)$ & $19(25.3)$ & - \\
\hline Adolescents (13-17) & $77(29.6)$ & $38(35.2)$ & $12(16.2)$ & $24(32.0)$ & - \\
\hline \multicolumn{2}{|l|}{ Sex $\ddagger$} & & & & 0.2 \\
\hline Female & $122(46.6)$ & $58(53.7)$ & $32(42.7)$ & $31(41.3)$ & - \\
\hline Male & $140(53.4)$ & $50(46.3)$ & $43(57.3)$ & $44(58.7)$ & - \\
\hline \multicolumn{2}{|l|}{ Population group§ } & & & & - \\
\hline White & $54(20.5)$ & $27(24.5)$ & $14(18.7)$ & $13(17.3)$ & 0.4 \\
\hline Black & $36(13.6)$ & $13(11.8)$ & $11(14.7)$ & $12(16.0)$ & 0.7 \\
\hline South Asian & $35(13.3)$ & $12(10.9)$ & $10(13.3)$ & $13(17.3)$ & 0.5 \\
\hline Arab/West Asian & $29(11.0)$ & $6(5.5)$ & $11(14.7)$ & $12(16.0)$ & 0.04 \\
\hline Indigenous & $24(9.1)$ & $14-17(12.7-15.5)^{\star \star}$ & $<5(<6.7)$ & $6(8.0)$ & 0.08 \\
\hline East/Southeast Asian & $12(4.5)$ & $<5(<4.5)$ & $<5(<6.7)$ & $<5(<6.7)$ & 0.8 \\
\hline Other & $6(2.3)$ & $<5(<4.5)$ & $<5(<6.7)$ & $<5(<6.7)$ & 0.9 \\
\hline Unknown & $72(27.3)$ & $33(30.0)$ & $21(28.0)$ & $14(18.7)$ & 0.2 \\
\hline \multicolumn{3}{|l|}{ Region of residence } & & & 0.1 \\
\hline Quebec & $114(43.2)$ & $44(40.0)$ & $39(52.0)$ & $27(36.0)$ & - \\
\hline Ontario & $94(35.6)$ & $37(33.6)$ & $26(34.7)$ & $31(41.3)$ & - \\
\hline Western/Northern 9 & $56(21.2)$ & $29(26.4)$ & $10(13.3)$ & $17(22.7)$ & - \\
\hline Atlantic & $0(0.0)$ & $0(0.0)$ & $0(0.0)$ & $0(0.0)$ & - \\
\hline \multicolumn{3}{|l|}{ Comorbid conditions } & & & 0.01 \\
\hline None or unknown & $163(62.7)$ & $72(65.5)$ & $55(73.3)$ & $36(48.0)$ & - \\
\hline 1 & $58(22.3)$ & $24(21.8)$ & $14(18.7)$ & $20(26.7)$ & - \\
\hline$\geq 2$ & $39(15.0)$ & $14(12.7)$ & $6(8.0)$ & $19(25.3)$ & - \\
\hline \multicolumn{6}{|c|}{$\begin{array}{l}\text { *We defined severity categories using criteria modified from Dong et al. }{ }^{15} \text { Nonsevere disease combines mild and moderate illness; severe disease combines severe } \\
\text { and critical illness. We could not assign severity categories for } 4 \text { cases because of incomplete reports. } \\
\text { tWe conducted statistical tests among admission not related to COVID-19, nonsevere COVID-19 and severe COVID-19 groups (3-way } \chi^{2} \text { or Fisher exact tests.). } \\
\text { †Age unavailable for } 4 \text { children ( } 2 \text { not related to COVID-19, } 1 \text { with nonsevere COVID-19 and } 1 \text { was not assigned a severity category). Sex was unavailable for } \\
2 \text { children ( } 2 \text { not related to COVID-19). } \\
\text { \$Physicians could report multiple population groups. East/Southeast Asian includes Chinese, Filipino, Japanese, Korean and Southeast Asian population groups. } \\
\text { Indigenous includes First Nations, Inuit and Métis. Statistical tests were conducted between cases with a population group indicated versus not indicated (e.g., White } \\
\text { v. not White and Black v. not Black). } \\
\text { IWestern/Northern includes } 26 \text { from Manitoba, } 18 \text { from Alberta, } 7 \text { from British Columbia and } 5 \text { from Saskatchewan, Northwest Territories or Nunavut. Atlantic } \\
\text { includes New Brunswick, Newfoundland and Labrador, Nova Scotia and Prince Edward Island. } \\
\text { **Some statistics are presented as a range to prevent back-calculation of }<5 \text { cell sizes. }\end{array}$} \\
\hline
\end{tabular}

SARS-CoV-2 infection did not differ significantly by sex, most population groups or region of residence; however, severe COVID-19 was more likely among children with comorbidities $(p=0.01)$ (Table 1).

Fewer than 5 children $(<1.9 \%)$ travelled out of their home province (within Canada or internationally) in the 12 weeks before symptom onset. There were 129 children (48.9\%) with a close contact who was known to be SARS-CoV-2 positive in the 8 weeks before symptom onset. Close contacts were most often parents $(n=99,76.7 \%)$, siblings $(n=28,21.7 \%)$ and other relatives $(n=13,10.1 \%)$. Twenty infections $(7.6 \%)$ were nosocomially acquired (10 in long-term care facilities and 10 in hospitals). 


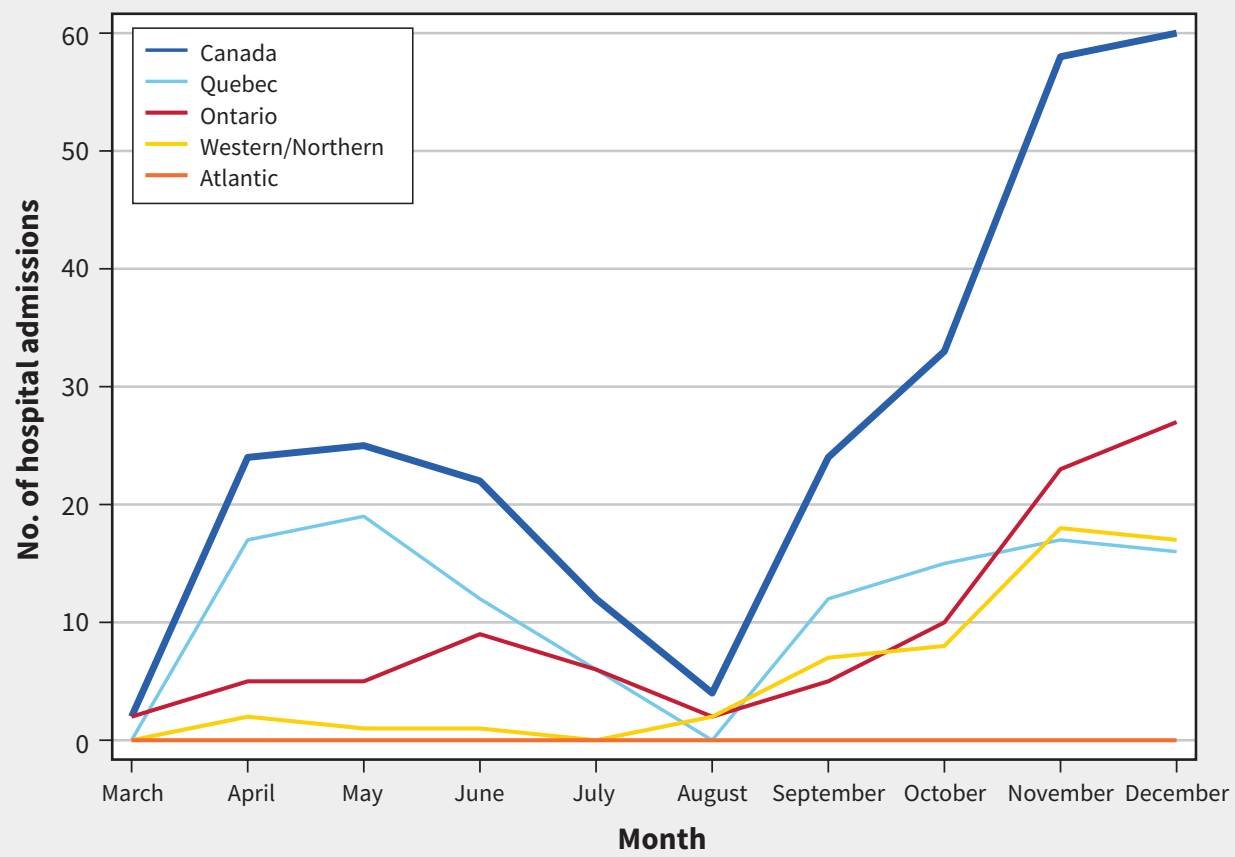

Figure 2: Hospital admissions for acute SARS-CoV-2 infections involving children, by calendar month and region of residence. Note: Number of new cases admitted in each month. Note: Western/Northern includes Alberta, British Columbia, Manitoba, Northwest Territories, Nunavut, Saskatchewan and Yukon. Atlantic includes Newfoundland and Labrador, New Brunswick, Nova Scotia and Prince Edward Island.

Seven children were reported to have a known contact at school or daycare, all of which occurred in September 2020 or later.

Categorization of cases is shown in Figure 1. Following investigator review, the cause of hospital admission remained unchanged from physician report in $93.6 \%$ of cases (Appendix 4, Supplementary Figure S1, available at www.cmaj.ca/lookup/ doi/10.1503/cmaj.210053/tab-related-content). Of the 264 cases, $150(56.8 \%)$ were admitted because of COVID-19. The remainder ( $n=114,43.2 \%$ ) included 100 children (87.7\%) who were admitted to hospital for other reasons who were found to have incidental SARS-CoV-2 infection on screening, 8 children (7.0\%) who were admitted for isolation or infection control after a positive result for a SARS-CoV-2 test and fewer than 5 children $(<4.4 \%)$ were admitted for social reasons. In fewer than 5 cases $(<1.9 \%)$, reason for admission was not specified and we could not categorize these because of insufficient data. Fifteen cases (5.7\%) concurrently met the CPSP case definition for hospital admission with acute SARS-CoV-2 infection and the case definition for pediatric inflammatory multisystem syndrome.

The most common symptoms among the 150 children who were admitted to hospital with COVID-19 were fever (70.0\%), vomiting (34.7\%) and cough (34.4\%) (Table 2). Common laboratory findings that were reported included lymphopenia (20.0\%), anemia (14.0\%) and neutropenia (13.3\%). Coagulopathy occurred in $12.7 \%$ of these children, hepatitis in $11.3 \%$ and cytokine storm in $6.7 \%$. Although fever was equally present in infants and older children (> $1 \mathrm{yr}$ ), older children were more likely to present with vomiting, anemia, pneumonia, hypotension, and subjective reports of headache and sore throat, whereas infants were more likely to present with runny nose, neutropenia or bronchiolitis. Appendix 5, Supplementary Table S2 (available at www.cmaj.ca/lookup/doi/10.1503/ cmaj.210053/tab-related-content) provides the clinical description of COVID-19 cases without those that also met the case definition of pediatric inflammatory multisystem syndrome.

Fifty-nine children (39.3\%) had at least 1 comorbidity (Table 3). Chronic encephalopathy with severe neurodisability (11 $n \leq 14)$, obesity ( $11 \leq n \leq 14)$, asthma ( $10 \leq n \leq 13)$, chronic lung disease (excluding asthma) $(10 \leq n \leq 13)$, epilepsy $(10 \leq n \leq 13)$ and neurodevelopmental disorders $(7 \leq n \leq 10)$ were the most common. Of children with epilepsy, 9 had a second neurologic or neurodevelopmental comorbidity reported, including 5 with cerebral palsy. There were no hospital admissions due to COVID-19 reported among children with inflammatory bowel disease, bone marrow transplantation or psychiatric conditions. Of children born prematurely $(9 \leq n \leq 12)$, median chronological age was 0.9 years (interquartile range [IQR] 0.0-2.6 yr) and median gestational age at birth was 30 weeks (IQR 28-34 wk). Hospital admissions related to COVID-19 rather than not related to COVID-19 were more likely for children with asthma $(6.7 \%-8.7 \% \mathrm{v} .<4.5 \%, p=0.03)$ or metabolic disease $(4.0 \%$ v. $0.0 \%, p=0.04)$ and less likely for children born prematurely $(6.5 \%-8.6 \%$ v. $18.7 \%, p=0.03)$ or with a psychiatric condition ( $0 \%$ v. $4.5 \%, p=0.01$ ) (Appendix 6, Supplementary Table S3, available at www.cmaj.ca/lookup/doi/10.1503/ cmaj.210053/tab-related-content). 
Table 2: Clinical symptoms at presentation and laboratory findings among children admitted to hospital because of COVID-19

\begin{tabular}{|c|c|c|c|}
\hline \multirow[b]{2}{*}{ Characteristic } & \multicolumn{2}{|c|}{$\begin{array}{c}\text { No. }(\%) \text { of children admitted } \\
\text { to hospital because of } \\
\text { COVID-19* }\end{array}$} & \multirow[b]{2}{*}{$p$ valuet } \\
\hline & $\begin{array}{c}\text { Infant } \\
(<1 \mathrm{yr}) \\
n=63\end{array}$ & $\begin{array}{c}\text { Older children } \\
\begin{array}{c}(1 \text { to }<18 \text { yr) } \\
n=86\end{array}\end{array}$ & \\
\hline \multicolumn{4}{|l|}{ Symptom } \\
\hline Fever & $44(69.8)$ & $61(70.9)$ & 0.9 \\
\hline Runny nose & $22(34.9)$ & $17(19.8)$ & 0.04 \\
\hline Loss of appetite & $21(33.3)$ & $25(29.1)$ & 0.6 \\
\hline Cough & $17(27.0)$ & $34(39.5)$ & 0.1 \\
\hline Vomiting & $15(23.8)$ & $36(41.9)$ & 0.02 \\
\hline Respiratory distress & $14(22.2)$ & $26(30.2)$ & 0.3 \\
\hline Lethargy & $13(20.6)$ & $16(18.6)$ & 0.8 \\
\hline Diarrhea & $12(19.1)$ & $10(11.6)$ & 0.2 \\
\hline Rash & $6(9.5)$ & 10 (11.6) & 0.7 \\
\hline Sneezing & $5(7.9)$ & $<5(<5.8)$ & 0.08 \\
\hline Sore throat & $<5(<7.9)$ & $20(23.3)$ & 0.001 \\
\hline Conjunctivitis & $<5(<7.9)$ & $6(7.0)$ & 1.0 \\
\hline Headache & $0(0.0)$ & $16(18.6)$ & $<0.001$ \\
\hline Muscle aches & $0(0.0)$ & $13(15.1)$ & 0.001 \\
\hline Loss of smell & $0(0.0)$ & $8(9.3)$ & 0.02 \\
\hline Loss of taste & $0(0.0)$ & $<5(<5.8)$ & 0.3 \\
\hline \multicolumn{4}{|l|}{ Laboratory finding } \\
\hline Neutropenia & $13(20.6)$ & $7(8.1)$ & 0.03 \\
\hline Lymphopenia & $8(12.7)$ & $22(25.6)$ & 0.05 \\
\hline Thrombocytosis & $5(7.9)$ & $<5(<5.8)$ & 0.5 \\
\hline Anemia & $<5(<7.9)$ & $18(20.9)$ & 0.005 \\
\hline \multicolumn{4}{|l|}{ Clinical syndrome } \\
\hline Bronchiolitis & $5(7.9)$ & $0(0.0)$ & 0.01 \\
\hline Pneumonia & $<5(<7.9)$ & $25(29.1)$ & 0.001 \\
\hline Hepatitis & $<5(<7.9)$ & $15(17.4)$ & 0.007 \\
\hline Coagulopathy & $<5(<7.9)$ & $14(16.3)$ & 0.07 \\
\hline ARDS & $<5(<7.9)$ & $8(9.3)$ & 0.08 \\
\hline Cardiac dysfunction & $<5(<7.9)$ & $6(7.0)$ & 0.2 \\
\hline Seizures & $<5(<7.9)$ & $6(7.0)$ & 0.2 \\
\hline Encephalopathy & $<5(<7.9)$ & $<5(<5.8)$ & 0.6 \\
\hline Hypotension & $0(0.0)$ & $17(19.8)$ & $<0.001$ \\
\hline Renal dysfunction & $0(0.0)$ & $12(14.0)$ & 0.002 \\
\hline Cytokine storm/MAS & $0(0.0)$ & 10 (11.6) & 0.005 \\
\hline
\end{tabular}

Note: ARDS = acute respiratory distress syndrome, MAS = macrophage activation syndrome.

*One child in whom the date of birth was missing could not be assigned to an age category.

tWe conducted the statistical tests between infants and older children.
Overall, $75(50.0 \%)$ children were categorized as having nonsevere disease and 75 (50.0\%) as having severe disease (Table 4). The proportion of infants admitted to hospital with COVID-19 who met criteria for severe disease was less than for children older than 1 year (33.4\% v. 62.8\%; $p=0.001$ ) (Table 4). Thirty-two cases $(21.3 \%)$ were admitted to ICU (including $<5$ to the neonatal ICU) and 9 required mechanical ventilation. Fewer than 5 children who were reported to CPSP died. Children who were admitted to hospital with severe disease (Table 3) were more likely to have an underlying comorbidity than children with nonsevere disease $(52.0 \%$ v. $26.7 \% ; p=0.001)$. Those with severe disease were also more likely to have several underlying comorbidities (v. 0 or 1 comorbidity, $n=19,25.3 \%$ ) than those with nonsevere disease $(n=6,8.0 \% ; p=0.005)$. Finally, children with severe disease were more likely to have epilepsy (v. none; $12.0 \% \mathrm{v} .<6.7 \% ; p=0.03$ ), chronic encephalopathies with severe neurodisability ( $v$. none; $13.3 \%$ v. < 6.7; $p=0.005$ ), obesity (v. not obese; $13.3 \%$ v. < 6.7\%; $p=0.04$ ), or chronic lung disease (excluding asthma; v. none; $12.0 \%$ v. $<6.7 \% ; p=0.009$ ). There was no difference in disease severity among children with immunosuppression compared with those who were immunocompetent $(<6.7 \%$ each; $p=1.00)$.

About 1 in 4 patients received systemic corticosteroids and 7 (4.7\%) received any of remdesivir, (hydroxy)chloroquine or other immunomodulators including biologics (Table 5). Eighty-one children (54.0\%) received systemic antibiotics, of whom $40.7 \%$ were infants and $6.2 \%$ had sickle cell disease. No patient received SARS-CoV-2 convalescent plasma or monoclonal antibodies, and no child was reported to have been enrolled in a clinical trial for COVID-19 treatment. Children with a severe presentation were more likely to have received azithromycin, corticosteroids, immunoglobulin and anticoagulation (Table 5).

\section{Interpretation}

We have described the clinical manifestations, characteristics, severity of disease and treatment of most children who were admitted to hospital with SARS-CoV-2 infection in Canada between Mar. 25 and Dec. 31, 2020. Although reporting to CPSP was voluntary, the engagement of pediatricians in Canada led to patient-level data being captured for about $70 \%$ of all children admitted to hospital with SARS-CoV-2 infection.

Our study shows that the clinical presentation and severity of disease caused by SARS-CoV- 2 infection were different in children than in adults in the first part of the COVID-19 pandemic in Canada. Although children have recently been shown to have the highest seroprevalence of SARS-CoV-2 antibodies from infection among all age groups in Canada (3.3\%), the relatively small number of pediatric hospital admissions highlights that children have less severe infection than adults even though they may be infected more frequently. ${ }^{18}$ Many children with SARS-CoV-2 infection in Canada were likely undiagnosed because they were asymptomatic and were consistently underrepresented in proportions of positive test results reported across provincial jurisdictions. ${ }^{19,20}$ Our finding that nearly half $(43.8 \%)$ of the children admitted to hospital with SARSCoV-2 infection were admitted for other medical reasons, social reasons or infection control purposes reinforces this assumption. 
Table 3: Associated factors and chronic comorbidities among children who were admitted to hospital because of COVID-19

\begin{tabular}{|c|c|c|c|}
\hline \multirow[b]{3}{*}{ Characteristic } & \multirow{2}{*}{\multicolumn{2}{|c|}{$\begin{array}{c}\text { No. }(\%) \text { of children admitted to } \\
\text { hospital because of COVID-19 } \\
\text { Clinical presentation* }\end{array}$}} & \multirow[b]{3}{*}{$p$ valuet } \\
\hline & & & \\
\hline & $\begin{array}{l}\text { Nonsevere disease } \\
\qquad n=75\end{array}$ & $\begin{array}{l}\text { Severe disease } \\
\qquad n=75\end{array}$ & \\
\hline Born premature $(<37 w k) \ddagger$ & $<5(<7.1)$ & $8(11.6)$ & 0.2 \\
\hline Any comorbid condition & $20(26.7)$ & $39(52.0)$ & 0.001 \\
\hline Chronic encephalopathy with severe neurodisability§ & $<5(<6.7)$ & $10(13.3)$ & 0.005 \\
\hline Obesity & $<5(<6.7)$ & $10(13.3)$ & 0.04 \\
\hline Asthma & $<5(<6.7)$ & $9(12.0)$ & 0.07 \\
\hline Chronic lung disease (excluding asthma) & $<5(<6.7)$ & $9(12.0)$ & 0.009 \\
\hline Epilepsy & $<5(<6.7)$ & $9(12.0)$ & 0.03 \\
\hline Gastrointestinal or liver disease & $<5(<6.7)$ & $7(9.3)$ & 0.2 \\
\hline Neurodevelopmental disorders§ & $<5(<6.7)$ & $6(8.0)$ & 0.7 \\
\hline Chronic renal disease & $<5(<6.7)$ & $<5(<6.7)$ & - \\
\hline Immunosuppression & $<5(<6.7)$ & $<5(<6.7)$ & - \\
\hline Metabolic disease & $<5(<6.7)$ & $<5(<6.7)$ & - \\
\hline Other congenital anomalies & $<5(<6.7)$ & $<5(<6.7)$ & - \\
\hline Other neurologic condition§ & $<5(<6.7)$ & $<5(<6.7)$ & - \\
\hline Sickle cell or other hematologic condition & $<5(<6.7)$ & $<5(<6.7)$ & - \\
\hline Malignant disease & $<5(<6.7)$ & $0(0.0)$ & 0.5 \\
\hline Solid organ transplant & $<5(<6.7)$ & $0(0.0)$ & 1.0 \\
\hline Congenital heart disease & $0(0.0)$ & $<5(<6.7)$ & 0.2 \\
\hline Diabetes & $0(0.0)$ & $<5(<6.7)$ & 0.5 \\
\hline Tracheostomy & $0(0.0)$ & $<5(<6.7)$ & 1.0 \\
\hline Bone marrow transplant & $0(0.0)$ & $0(0.0)$ & - \\
\hline Inflammatory bowel disease & $0(0.0)$ & $0(0.0)$ & - \\
\hline Psychiatric condition & $0(0.0)$ & $0(0.0)$ & - \\
\hline Concurrent infection & & & 0.2 \\
\hline Infection explains some or all COVID-19 symptoms & $<5(<6.7)$ & $7(9.3)$ & - \\
\hline $\begin{array}{l}\text { Concurrent infection is deemed to be incidental } \\
\text { and all symptoms explained by COVID-19 }\end{array}$ & $<5(<6.7)$ & $5(6.7)$ & - \\
\hline $\begin{array}{l}\text { *We defined clinical presentation using criteria modified from Dong et } \\
\text { disease combines severe and critical illness. } \\
\text { tWe conducted statistical tests between the nonsevere and severe dis } \\
\text { frequency is presented. } \\
\text { †Prematurity status was known for } 139 \text { children (including } 70 \text { nonseve } \\
\text { \$Chronic encephalopathy with severe neurodisability includes condit } \\
\text { classification system 5) and cognitive impairments. Neurodevelopmer } \\
\text { disorder, autism spectrum disorder and trisomy } 21 \text {. Other neurologic } \\
\text { chronic encephalopathy, metabolic, neurodevelopmental or psychiat }\end{array}$ & $\begin{array}{l}\text { Nonsevere disease combin } \\
\text { groups. We show } p \text { values } \\
\text { d } 69 \text { severe cases). } \\
\text { causing substantial motor ( } \\
\text { isorders include condition } \\
\text { itions were those that we d }\end{array}$ & $\begin{array}{l}\text { mild and moderate illt } \\
\text { y for cases in which at } \\
\text { Palisano gross motor } \\
\text { ch as attention-defici } \\
\text { ot otherwise categori }\end{array}$ & $\begin{array}{l}\text { ss; severe } \\
\text { ast } 1 \text { exact } \\
\text { unction } \\
\text { nyperactivity } \\
\text { as as }\end{array}$ \\
\hline
\end{tabular}

Among children admitted to hospital for COVID-19, half $(50.0 \%)$ were categorized as having severe disease, $21.3 \%$ required admission to ICU and $13.3 \%$ required cardiac or respiratory support greater than low-flow oxygen

Our findings suggest a different pattern of severity compared with previous pediatric studies. A 2020 descriptive study involving 130 children in Italy who were admitted to hospital with
COVID-19 found that $15.4 \%$ had severe or critical disease..$^{21}$ Differences in classification of asymptomatic patients (incidental SARS-CoV-2 infection in our analysis) may explain the different findings. The rate of admissions to ICU in our study was higher than that reported in a 2020 systematic review ${ }^{22}$ but similar to those found in a large, multicentre prospective observational cohort study in the United Kingdom. ${ }^{23}$ Different clinical 
Table 4: Illness severity, support provided and radiographic findings among children admitted to hospital because of COVID-19

\begin{tabular}{|c|c|c|c|c|}
\hline \multirow[b]{3}{*}{ Characteristic } & \multicolumn{3}{|c|}{$\begin{array}{l}\text { No. }(\%) \text { of children admitted to hospital } \\
\text { because of COVID-19 }\end{array}$} & \multirow[b]{3}{*}{$p$ value $\dagger$} \\
\hline & \multirow[b]{2}{*}{$\begin{array}{l}\text { All cases } \\
n=150\end{array}$} & \multicolumn{2}{|c|}{ Age $^{\star}$} & \\
\hline & & $\begin{array}{l}\text { Infant } \\
\text { (<1 yr) } \\
n=63\end{array}$ & $\begin{array}{c}\text { Older children } \\
\begin{array}{c}(1 \text { to }<18 \text { yr }) \\
n=86\end{array}\end{array}$ & \\
\hline Clinical presentation $\ddagger$ & & & & 0.001 \\
\hline Mild illness & $44(29.3)$ & $25(39.7)$ & $19(22.1)$ & - \\
\hline Moderate illness & $31(20.7)$ & $17(27.0)$ & $13(15.1)$ & - \\
\hline Severe illness & $23(15.3)$ & $10(15.9)$ & $13(15.1)$ & - \\
\hline Critical illness & $52(34.7)$ & $11(17.5)$ & $41(47.7)$ & - \\
\hline Respiratory or hemodynamic support required & $42(28.0)$ & $10(15.9)$ & $32(37.2)$ & 0.004 \\
\hline Low-flow oxygen & $23(15.3)$ & $7(11.1)$ & $16(18.6)$ & 0.2 \\
\hline High-flow nasal cannula & $14(9.3)$ & $0(0.0)$ & $14(16.3)$ & $<0.001$ \\
\hline Noninvasive ventilation (e.g., CPAP or BiPAP) & $8(5.3)$ & $<5(<7.9)$ & $5-7(5.8-8.1) \S$ & 1.0 \\
\hline Conventional mechanical ventilation & $9(6.0)$ & $<5(<7.9)$ & $5-8(5.8-9.3) \S$ & 0.7 \\
\hline High-frequency oscillatory ventilation & $<5(<3.3)$ & $<5(<7.9)$ & $0(0.0)$ & 0.4 \\
\hline Nitric oxide & $<5(<3.3)$ & $0(0.0)$ & $<5(<5.8)$ & 1.0 \\
\hline Vasopressors & $8(5.3)$ & $0(0.0)$ & $8(9.3)$ & 0.02 \\
\hline Admitted to ICU & $32(21.3)$ & $6(9.5)$ & $26(30.2)$ & 0.002 \\
\hline \multicolumn{5}{|l|}{ Radiographic findings, $n /$ patients with imaging, $\%$} \\
\hline Abnormal chest radiograph & $40 / 103(38.8)$ & $12 / 41(29.3)$ & $27 / 61(44.3)$ & 0.1 \\
\hline Abnormal CT & $7 / 15(46.7)$ & $0(0.0)$ & $7 / 15(46.7)$ & - \\
\hline Died & $<5(<3.3)$ & $0(0.0)$ & $<5(<5.8)$ & 1.0 \\
\hline \multicolumn{5}{|c|}{$\begin{array}{l}\text { Note: BiPAP = bilevel positive airway pressure, CPAP = continuous positive airway pressure, } \mathrm{CT}=\text { computed tomography, ICU = intensive care unit. } \\
\text { "We could not assign an age category for } 1 \text { child for whom the date of birth was missing. } \\
\text { †We conducted statistical tests between infants and older children. We imputed missing or unknown data to the null value, and the proportion } \\
\text { of missing or unknown values was < } 5 \% \text { for all variables. } \\
\text { łWe defined severity categories using criteria modified from Dong et al }{ }^{15} \text { and definitions are listed in Appendix } 2 \text { (available at www.cmaj.ca/ } \\
\text { lookup/doi/10.1503/cmaj.210053/tab-related-content). } \\
\text { §Some statistics are presented as a range to prevent back-calculation of < } 5 \text { cell sizes. }\end{array}$} \\
\hline
\end{tabular}

approaches across jurisdictions early in the pandemic, including tendencies to admit patients to ICU for close monitoring rather than for cardiac or respiratory support may explain differences in studies' findings.

Similar to several published studies, deaths due to COVID-19 were rare in our study. ${ }^{24}$ Our findings align with findings from recent studies ${ }^{8,21,25}$ and a meta-analysis ${ }^{26}$ that suggested that children with certain comorbidities may be at higher risk of severe COVID-19.

Also similar to other studies, we found that most children admitted to hospital with acute COVID-19 required only supportive care, with only a few receiving targeted therapy for COVID-19 such as remdesivir, (hydroxy)chloroquine, biologic agents, anticoagulation, steroids or immunoglobulins. ${ }^{27}$ Although this may reflect the less severe nature of the disease in children, evolving evidence for these interventions in the pediatric age group may have also played a role. Of note, none of the children in this study were enrolled in any of the available clinical trials for children with COVID-19 in Canada, highlighting the challenges in conducting clinical trials in children and explaining, in part, the lack of an evidence base to guide pediatric care.

Our findings suggest a bimodal age distribution with peaks among infants and teenagers. Higher minimum incidence of hospital admissions for COVID-19 among infants, combined with observed smaller proportions with severe disease, may be explained by 2 factors. First, physicians seeing those patients may have applied greater caution among those patients (opting to admit to hospital for observation rather than discharging to home). Second, in many institutions, it is standard practice to admit to hospital any child younger than 6-12 weeks of age who presents with fever. ${ }^{24,28,29}$ These factors may also explain why our findings differ from other studies that reported that infants ( $<1 \mathrm{yr}$ ) were at higher risk of severe disease. ${ }^{21,22}$ The higher proportion of cases among teenagers may reflect more severe disease in this 
Table 5: Treatments administered to children who were admitted to hospital because of COVID-19

\begin{tabular}{|c|c|c|c|}
\hline \multirow[b]{3}{*}{ Characteristic } & \multirow{2}{*}{\multicolumn{2}{|c|}{$\begin{array}{l}\text { No. }(\%) \text { of children } \\
\text { admitted to hospital } \\
\text { because of COVID-19 }\end{array}$}} & \multirow[b]{3}{*}{$\begin{array}{c}p \\
\text { value† }\end{array}$} \\
\hline & & & \\
\hline & $\begin{array}{c}\text { Nonsevere } \\
\text { disease } \\
n=75\end{array}$ & $\begin{array}{c}\text { Severe } \\
\text { disease } \\
n=75\end{array}$ & \\
\hline \multicolumn{4}{|l|}{ Type of treatment } \\
\hline $\begin{array}{l}\text { Antibiotic } \\
\text { (e.g., ceftriaxone) } \ddagger\end{array}$ & $35(46.7)$ & $46(61.3)$ & 0.07 \\
\hline Steroid & $<5(<6.7)$ & $32(42.7)$ & $<0.001$ \\
\hline Immunoglobulin (IV) & $<5(<6.7)$ & $15(20.0)$ & 0.003 \\
\hline Bronchodilator & $<5(<6.7)$ & $14(18.7)$ & 0.005 \\
\hline Anticoagulation§ & $<5(<6.7)$ & $11(14.7)$ & 0.009 \\
\hline Azithromycin & $0(0.0)$ & $9(12.0)$ & 0.003 \\
\hline ASA & $<5(<6.7)$ & $8(10.7)$ & 0.1 \\
\hline Antiviral§ & $<5(<6.7)$ & $5(6.7)$ & 0.7 \\
\hline Biologic§ & $0(0.0)$ & $<5(<6.7)$ & 0.5 \\
\hline Chloroquine§ & $0(0.0)$ & $<5(<6.7)$ & 0.1 \\
\hline Enrolled in a clinical trial & $0(0.0)$ & $0(0.0)$ & - \\
\hline \multicolumn{4}{|c|}{$\begin{array}{l}\text { Note: ASA = acetylsalicylic acid, IL = interleukin, IV = intravenous administration, TNF = } \\
\text { tumour necrosis factor. } \\
\text { *We defined clinical presentation using criteria modified from Dong et al. }{ }^{15} \text { Nonsevere } \\
\text { disease combines mild and moderate illness; severe disease combines severe and } \\
\text { critical illness. } \\
\text { tWe conducted statistical tests between the nonsevere and severe disease groups. We } \\
\text { imputed missing or unknown data to the null value, and the proportion of missing or } \\
\text { unknown values was < 5\% for all variables. } \\
\text { fIncludes azithromycin. All patients given azithromycin were also given another antibiotic. } \\
\text { \$Anticoagulation includes mechanical, prophylactic and therapeutic anticoagulation. } \\
\text { Antiviral includes remdesivir and other antivirals. Biologic includes anti-TNF, anti-IL-1 } \\
\text { and anti-IL-6. Chloroquine includes chloroquine and hydroxychloroquine. }\end{array}$} \\
\hline
\end{tabular}

age group. This group may also be at increased risk of acquiring infection compared with younger children. ${ }^{24,30}$

Although the number of children in this study with specific comorbidities was small, the absence of reported cases of children with any immune compromise (e.g., malignant disease, transplant recipients and those undergoing immunosuppressive therapy) may be cause for cautious optimism, but a relatively large number of children with neurologic conditions were reported. Further research on characteristics of this heterogeneous group is needed to determine whether certain populations (e.g., children with cerebral palsy or neurodevelopmental disability) are at increased risk from underlying medical complexity, unique exposure risks (e.g., multiple medical caregivers in home and school or residence in long-term care facilities) or a combination of both. ${ }^{31}$ As more data are reported, it will be important to track the clinical course of children with risk factors for severe disease from other respiratory viruses such as children born prematurely or those with asthma and other chronic respiratory conditions and any differences in severity associated with SARS-CoV-2 variants.

\section{Limitations}

Our study is limited by the voluntary reporting of the CPSP. Furthermore, complete case reporting was not possible from Alberta. As SARS-CoV-2 testing protocols varied by jurisdiction and throughout the study period and were limited in the early months of the pandemic to only symptomatic children, the total number of children admitted to hospital with incidental infection may be underestimated. We are unable to comment on the severity of identified underlying comorbidities and the numbers of reported cases with each comorbidity and risk factor precluded from conducting multivariable regression analyses to adjust for possible confounders. Although we described the distribution of cases by population group, we are unable to draw any conclusions because this variable was not reported by families. Finally, we conducted this study when substantial public health measures, including those related to physical distancing, were in place across the country and before the introduction of SARS-CoV-2 variants of concern to Canada. Changes to physical distancing practices and viral evolution may affect the epidemiology of COVID-19 in children. Nonetheless, our study was able to identify causes of admission and distinguish between incidental hospital admissions and those related to COVID-19 among children in Canada.

\section{Conclusion}

We found that the overall number of children admitted to hospital with SARS-CoV-2 infection in Canada was low, and nearly half of identified infections were incidental. As the pandemic continues to unfold, vigilance about potential changes in the epidemiology of SARS-CoV-2 infection in children is needed. A better understanding of overall disease severity in children, and at-risk groups of children, is important for plans related to future implementation of SARS-CoV-2 vaccines and prioritization in this age group.

\section{References}

1. Coronavirus disease (COVID-19): outbreak update. Ottawa: Public Health Agency of Canada; modified 2021 July 9. Available: https://www.canada.ca/en/public -health/services/diseases/2019-novel-coronavirus-infection.html\#a1 (accessed 2020 Nov. 30).

2. Kakkar F, Hepburn CM, Drouin O, et al.; Canadian Paediatric Surveillance Program, COVID-19 Study Team. Canadian Paediatric Surveillance Program commentary on hospitalizations from COVID-19 among children in Canada. Ottawa: Canadian Paediatric Surveillance Program; 2020.

3. Viner RM, Mytton OT, Bonell C, et al. Susceptibility to SARS-CoV-2 infection among children and adolescents compared with adults: a systematic review and meta-analysis. JAMA Pediatr 2021;175:143-56.

4. Bi Q, Wu Y, Mei S, et al. Epidemiology and transmission of COVID-19 in 391 cases and 1286 of their close contacts in Shenzhen, China: a retrospective cohort study. Lancet Infect Dis 2020;20:911-9.

5. Zimmermann $\mathrm{P}$, Curtis $\mathrm{N}$. Coronavirus infections in children including COVID19: an overview of the epidemiology, clinical features, diagnosis, treatment and prevention options in children. Pediatr Infect Dis J 2020;39:355-68.

6. Shekerdemian LS, Mahmood NR, Wolfe KK, et al.; International COVID-19 PICU Collaborative. Characteristics and outcomes of children with coronavirus disease 2019 (COVID-19) infection admitted to US and Canadian pediatric intensive care units. JAMA Pediatr 2020;174:868-73.

7. Zheng Z, Peng F, Xu B, et al. Risk factors of critical \& mortal COVID-19 cases: a systematic literature review and meta-analysis. J Infect 2020;81:e16-25. 
8. Preston LE, Chevinsky JR, Kompaniyets L, et al. Characteristics and disease severity of US children and adolescents diagnosed with COVID-19. JAMA Netw Open 2021;4:e215298.

9. Tuckerman J, Misan S, Crawford NW, et al. Influenza in children with special risk medical conditions: a systematic review and meta-analysis. Pediatr Infect Dis J 2019;38:912-9.

10. Shi T, Balsells E, Wastnedge E, et al. Risk factors for respiratory syncytial virus associated with acute lower respiratory infection in children under five years: systematic review and meta-analysis. J Glob Health 2015;5:020416.

11. About the CPSP. Ottawa: Canadian Paediatric Surveillance Program. Available: https://www.cpsp.cps.ca/about-apropos (accessed 2020 Nov. 30)

12. Number of physicians by province/territory and specialty, Canada, 2018. Ottawa: Canadian Medical Association. Available: https://www.cma.ca/sites/ default/files/pdf/Physician\%20Data/01-physicians-by-specialty-province-e.pdf (accessed 2020 Nov. 30).

13. Tam H, El Tal T, Go E, et al. Pediatric inflammatory multisystem syndrome temporally associated with COVID-19: a spectrum of diseases with many names. CMAJ 2020;192:E1093-6.

14. Morris S, Kakkar F, Moore Hepburn C. COVID-19: 2020-2021-current. Ottawa: Canadian Paediatric Surveillance Program. Available: https://www.cpsp.cps.ca /surveillance/study-etude/covid-19/ (accessed 2020 Oct. 20).

15. Dong Y, Mo X, Hu Y, et al. Epidemiology of COVID-19 among children in China. Pediatrics 2020;145:e20200702.

16. Clinical spectrum of SARS-CoV-2 infection. Bethesda (MD): National Institutes of Health; 2021. Available: https://www.covid19treatmentguidelines.nih.gov/ overview/clinical-presentation/ (accessed 2020 Nov. 24).

17. Table 17-10-0005-01: Population estimates on July 1st, by age and sex. Ottawa: Statistics Canada. Available: https://www150.statcan.gc.ca/t1/tbl1/ en/cv.action?pid=1710000501 (accessed 2020 Nov. 24).

18. Study reveals children and youth had highest rates of SARS-CoV-2 infection in Canada before third wave [news release]. Montréal: COVID-19 Immunity Task Force; 2021 July 6; Available: https://www.covid19immunitytaskforce.ca/ study-reveals-children-and-youth-had-highest-rates-of-sars-cov-2-infection-in -canada-before-third-wave/ (accessed 2021 Aug. 2).

19. Portrait de la COVID-19 parmi les enfants du Québec du 23 février au 11 juillet 2020. Institut national de santé publique du Québec; 2021. Available: https:// www.inspq.qc.ca/publications/3081-portrait-enfants-covid19 (accessed 2021 Aug. 3).
20. Ontario Agency for Health Protection and Promotion (Public Health Ontario) COVID-19 infection in children: January 15, 2020 to June 30, 2021. Toronto: Queen's Printer for Ontario; 2021. Available: https://www.publichealthontario. ca/-/media/documents/ncov/epi/2020/05/covid-19-epi-infection-children.pdf? sc_lang=en (accessed 2021 Aug. 3).

21. Parri N, Magistà AM, Marchetti F, et al.; CONFIDENCE and COVID-19 Italian Pediatric Study Networks. Characteristic of COVID-19 infection in pediatric patients: early findings from two Italian Pediatric Research Networks. Eur J Pediatr 2020;179:1315-23.

22. Liguoro I, Pilotto $\mathrm{C}$, Bonanni $\mathrm{M}$, et al. SARS-CoV-2 infection in children and newborns: a systematic review. Eur J Pediatr 2020;179:1029-46.

23. Swann OV, Holden KA, Turtle L, et al.; ISARIC4C Investigators. Clinical characteristic of children and young people admitted to hospital with COVID-19 in United Kingdom: prospective multicentre observational cohort study. BMJ 2020;370:m3249.

24. Bellino S, Punzo O, Rota MC, et al.; COVID-19 Working Group. COVID-19 disease severity risk factors for pediatric patients in Italy. Pediatrics 2020;146:e2020009399. doi: 10.1542/peds.2020-009399.

25. Leeb RT, Price S, Sliwa S, et al. COVID-19 trends among school-aged children: United States, March 1-September 19, 2020. MMWR Morb Mortal Wkly Rep 2020;69:1410-5.

26. Tsankov BK, Allaire JM, Irvine MA, et al. Severe COVID-19 infection and pediatric comorbidities: a systematic review and meta-analysis. Int J Infect Dis 2021;103: 246-56.

27. Götzinger F, Santiago-García B, Noguera-Julián A, et al.; ptbnet COVID-19 Study Group. COVID-19 in children and adolescents in Europe: a multinational, multicentre cohort study. Lancet Child Adolesc Health 2020;4:653-61.

28. Panetta L, Proulx C, Drouin O, et al. Clinical characteristics and disease severity among infants with SARS-CoV-2 infection in Montreal, Quebec, Canada. JAMA Netw Open 2020;3:e2030470.

29. Burstein B, Gravel J, Aronson PL, et al.; Pediatric Emergency Research Canada (PERC). Emergency department and inpatient clinical decision tools for the management of febrile young infants among tertiary paediatric centres across Canada. Paediatr Child Health 2019;24:e142-54.

30. Bailey LC, Razzaghi H, Burrows EK, et al. Assessment of 135794 pediatric patients tested for severe acute respiratory syndrome coronavirus 2 across the United States. JAMA Pediatr 2021;175:176-84.

31. Burton C, Vaudry W, Moore D, et al.; IMPACT investigators. Burden of seasonal influenza in children with neurodevelopmental conditions. Pediatr Infect Dis J 2014;33:710-4
Competing interests: Krista Baerg reports funding from the Chronic Pain Network. She also served as Past President of the Community Paediatrics Section of the Canadian Paediatric Society and on the Board of Directors for Saskatchewan Pain Society, and has received royalties from Brush Education. Kevin Chan is Chair of the Acute Care Committee of the Canadian Paediatric Society. Elizabeth Donner is Chair of the Scientific Research Committee and a director of Epilepsy Canada. She is also a member of Partners Against Mortality in Epilepsy and the advisory boards of Cardiol, Pendopharm and Stoke Therapeutics. Catherine Farrell is Chair of the Scientific Steering Committee for the Canadian Paediatric Surveillance Program, former Chair of the Specialty Committee in Pediatrics of the Royal College of Physicians and Surgeons of Canada, former President of the Canadian Paediatric Society, and Chair of the Ethics Committee and a member of the Board of Directors of the Canadian Critical Care Society. She has received reimbursement for travel expenses from Canadian Paediatric Society and the Royal College of Physicians and Surgeons of Canada. She has also received an honorarium for a presentation at a continuing education conference from the Université de Sherbrooke. Sarah Forgie is the President of the Association of Medical Microbiology and Infectious Disease Canada. Fatima Kakkar has received honoraria for presentations given to the Association des
Pédiatres du Québec. Thuy Mai Luu is the Director of the Canadian Neonatal Follow-Up Network. Charlotte Moore Hepburn is the Director of Children's Mental Health of Ontario, and the Director of medical affairs for the Canadian Paediatric Society and the Canadian Paediatric Surveillance Program. Shaun Morris has received honouraria for lectures from GlaxoSmithKline. He was a member of an ad hoc advisory board for Pfizer Canada. Jesse Papenburg has received consultant fees from AbbVie, honouraria from AbbVie and Seegene, and he received respiratory virus testing materials from Seegene for his institution. He has participated in ad hoc advisory board meetings for AbbVie and is a voting member of the National Advisory Committee on Immunization. Rupeena Purewal is a consultant for Verity Pharmaceuticals. Manish Sadarangani is a member of the advisory board of Astra Zeneca. Marina Salvadori is an employee of the Public Health Agency of Canada. No other competing interests were declared.

This article has been peer reviewed.

Affiliations: Divisions of General Pediatrics (Drouin, Luu) and Pediatric Intensive Care (Farrell), Department of Pediatrics, and Division of Infectious Diseases (Kakkar), Centre Hospitalier Universitaire SainteJustine; Department of Social and Preventive Medicine (Drouin), 
School of Public Health, Université de Montréal, Montréal, Que.; Division of Paediatric Medicine (Moore Hepburn, Giroux, Orkin), Centre for Global Child Health (Farrar, Morris) and Child Health Evaluative Sciences (Morris, Orkin), The Hospital for Sick Children; Institute of Health Policy, Management and Evaluation (Moore Hepburn), and Departments of Pediatrics (Chan) and Clinical Public Health (Morris), Dalla Lana School of Public Health, University of Toronto, Toronto, Ont.; Department of Pediatrics (Baerg, Purewal), University of Saskatchewan; Divisions of General Paediatrics (Baerg) and Pediatric Infectious Diseases (Purewal), Jim Pattison Children's Hospital, Saskatchewan Health Authority, Saskatoon, Sask.; Department of Children's and Women's Health (Chan), Trillium Health Partners, Mississauga, Ont.; Service de soins intensifs pédiatriques (Cyr), Centre Hospitalier, and Faculté de médecine (Cyr), Université de Sherbrooke, Sherbrooke, Que.; Departments of Paediatrics and Child Health (Embree), and Medical Microbiology and Infectious Diseases (Embree), University of Manitoba, Winnipeg, Man.; Division of Infectious Diseases (Forgie), Department of Pediatrics, University of Alberta; Stollery Children's Hospital (Forgie), Edmonton, Alta.; Department of Pediatrics (Sadarangani, Tang), University of British Columbia, Vancouver, BC; Canadian Paediatric Surveillance Program (King, Laffin), Canadian Paediatric Society, Ottawa, Ottawa, Ont.; Division of Pediatric Infectious Diseases (Papenburg), Department of Pediatrics, Montreal Children's Hospital; Division of Microbiology (Papenburg), Department of Clinical Laboratory Medicine, McGill University Health Centre, Montréal, Que.; Division of General Pediatrics (Pound), Department of Pediatrics, Children's Hospital of Eastern Ontario, Ottawa, Ont.; Division of Pediatric Hematology/Oncology (Price), Department of Pediatrics, Dalhousie University, Halifax, NS; Vaccine Evaluation Center (Sadarangani), BC Children's Hospital Research Institute, Vancouver, BC; Public Health Agency of Canada (Salvadori), Ottawa, Ont.; Department of Pediatrics (Top), Dalhousie University, Halifax, NS; Division of Infectious Diseases (Viel-Thériault), Department of Pediatrics, CHU de Québec-Université Laval, Québec, Que.; Divisions of Infectious Diseases (Morris) and Neurology (Donner), The Hospital for Sick Children; University of Toronto, Toronto, Ont.

Contributors: The study was conceived by Olivier Drouin, Charlotte Moore Hepburn, Daniel Farrar, Fatima Kakkar and Shaun Morris. Olivier Drouin wrote the first draft of the manuscript. Analysis was conducted by Daniel Farrar. All of the authors contributed to data collection and interpretation, reviewed the manuscript critically for important intellectual content, gave final approval of the version to be published and agreed to be accountable for all aspects of the work.
Content licence: This is an Open Access article distributed in accordance with the terms of the Creative Commons Attribution (CC BY-NC-ND 4.0) licence, which permits use, distribution and reproduction in any medium, provided that the original publication is properly cited, the use is noncommercial (i.e., research or educational use), and no modifications or adaptations are made. See: https://creativecommons.org/licenses/by-nc-nd/4.0/

Funding: Elizabeth Donner has received a grant from the Ontario Brain Institute. Catherine Farrell has received a grant from Health Canada. Olivier Drouin, Jesse Papenburg, Thuy Mai Luu and Fatima Kakkar are supported by a Clinical Research Scholars Award from the Fonds de recherche du Québec - Santé. Shaun Morris has received an investigatorled grant from Pfizer Canada. Jesse Papenburg has received grants (paid to his institution) from MedImmune, Sanofi Pasteur and AbbVie. Manish Sadarangani has received grants (paid to his institution) from GlaxoSmithKline, Merck, Pfizer, Sanofi Pasteur, Seqirus, Symvivo and VBI Vaccines. He also receives financial support through salary awards from the BC Children's Hospital Foundation, the Canadian Child Health Clinician Scientist Program and the Michael Smith Foundation for Health Research. Karina Top has received grants from GlaxoSmithKline. Financial support for the Canadian Paediatric Surveillance Program was received from the Public Health Agency of Canada (Morris) in support of this COVID-19 study.

Data sharing: De-identified data that underlie the results reported in this article (text, tables, figures and appendices) and that abide by the privacy rules of the Canadian Paediatric Surveillance Program and the Public Health Agency of Canada will be made available to investigators whose secondary data analysis study protocol has been approved by an independent research ethics board. Proposals should be directed to shaun. morris@sickkids.ca; to gain access, data requestors will need to sign a data access agreement.

Acknowledgements: The authors thank the pediatricians, pediatric subspecialists and health professionals who voluntarily respond to Canadian Paediatric Surveillance Program (CPSP) surveys. They also thank Dr. Jim Kellner for his guidance and support, as well as the members and leadership of the Paediatric Inpatient Research Network for cases reported and their dedication to the CPSP. The authors are grateful to the staff of the CPSP for their dedication, diligence and commitment to this study. The authors also thank members of the CPSP Scientific Steering Committee who serve as stewards of the program.

Accepted: Aug. 17, 2021

Correspondence to: Shaun Morris, shaun.morris@sickkids.ca; Fatima Kakkar, fatima.kakkar@umontreal.ca 